\title{
Pensamento negro e educação intercultural no Brasil
}

\author{
Silva, Claudilene ${ }^{1}$ \\ Santiago, Eliete ${ }^{2}$
}

\section{Resumo}

A despeito de a população negra constituir a maioria da população brasileira, o desejo de branqueamento do Brasil ainda invisibiliza essa população em diversos campos da sociedade, inclusive na educação. Entretanto, autoras/es referenciais no campo da pesquisa sobre Educação e Relações Raciais defendem que a população negra no Brasil sempre se preocupou com a educação de suas crianças e adolescentes expressando suas concepções e orientações. Indagamos se é possível reconhecer nas experiências educacionais negras elementos constitutivos de uma pedagogia decolonial e se práticas educativas vivenciadas por esses movimentos podem ser consideradas na gênese da luta por uma educação intercultural no Brasil. Para avançar com essas questões, utilizamo-nos de um estudo bibliográfico, e os resultados apontam que o pensamento negro em educação no Brasil dialoga com conceitos fundamentais da educação intercultural. Sua trajetória evidencia a existência de uma constante tensão entre a manutenção da lógica eurocêntrica e a proposição epistêmica dos descendentes de africanos no Brasil.

Pensamento Negro. Pensamento decolonial. Educação. Interculturalidade.

\section{Resumen}

A pesar de que la población negra constituye la mayoría de la población brasilera, el deseo de blanqueamiento del Brasil todavia invisibiliza esa población en diversos campos de la sociedad, inclusive en la educación. Entretanto, autoras/es referenciales en elcampo de la investigación sobre Educación y Relaciones Raciales, defienden que la población negra en Brasil siempre se preocupó con la educación de sus niños y adolescentes expresando sus concepciones y orientaciones. Indagamos si es posible reconocer en las experiencias educativas negras elementos constitutivos de una pedagogia decolonial, si prácticas educativas vivenciadas por esos movimientos pueden ser consideradas en la génesis de la lucha por una educación intercultural en Brasil. Para avanzar en esos asuntos, nos servimos de um estudio bibliográfico, y los resultados apuntan a que el pensamiento negro en la educación en Brasil dialoga com conceptos fundamentales de la educación intercultural. Su trayectoria evidencia la existencia de una constante tensión entre el mantenimiento de la lógica eurocéntrica y la proposición epistémica de los descendientes de africanos en Brasil.

Pensamiento negro. Pensamiento Decolonial. Educación. Interculturalidad.

\footnotetext{
1 Doutora em Educação, professora adjunta da Universidade da Integração Internacional da Lusofonia Afro-Brasileira - UNILAB Instituto de Humanidades e Letras - Campus dos Malês São Francisco do Conde/BA. E-mail: claudilenems@unilab.edu.br

2 Doutora em Ciências da Educação, professora titular do Departamento de Administração Escolar e Planejamento Educacional do Centro de Educação da UFPE. Coordenadora da Cátedra Paulo Freire da UFPE. E-mail: mesantiago@uol.com.br
} 


\section{Introdução}

O Brasil é o segundo país do mundo em população negra, ficando atrás apenas da Nigéria, no continente africano. A despeito de a população negra constituir a maioria da população brasileira, o desejo de branqueamento do Brasil ainda invisibiliza essa população em diversos campos da sociedade, inclusive na educação. Ao mesmo tempo, existe um movimento contrário que busca visibilizar os descendentes de africanos no Brasil, suas formas de existência, organização e inserção cultural, política, social e educacional.

No campo da pesquisa científica, é somente a partir dos últimos 30 anos que a população negra começa a passar de objeto a sujeito de investigação ${ }^{3}$. Todavia, existe uma vasta produção cultural e intelectual de autoria dos mais variados grupos sociais de maioria negra que foi desconsiderada ao longo da história do Brasil, mas que começa a ganhar força na atualidade. Do ponto de vista teórico e epistemológico, afirma Cunha Jr. (2006) que os pesquisadores/as negros/as interessados em temas específicos da população negra podem ser agrupados em três tendências conceituais: aqueles/as que se abrigaram nos conceitos werberiano e americanos de raça e raça social; aqueles/as que seguiram a tendência nacional de uma tentativa de composição entre raça social e classe social; e aqueles/as que estavam procurando a produção de um conhecimento de ruptura com a hegemonia do pensamento eurocêntrico.

A perspectiva epistêmica dos estudos pós-coloniais latino-americanos tem se mostrado para uma parcela de pesquisadoras/es que compõem esse terceiro grupo como uma possibilidade de fundamentação de suas pesquisas, uma vez que o pensamento decolonial deseja fundar um pensamento "outro" (WALSH, 2008) que afirme a necessidade de mudar não só as relações, mas também as estruturas, condições e dispositivos de poder que mantêm a desigualdade, inferiorização, racialização e discriminação, inclusive no âmbito educacional.

\footnotetext{
${ }^{3}$ Citando Guerreiro Ramos, Gonçalves e Gonçalves e Silva (2004, p. 93), ao afirmarem que "os sociólogos brasileiros haviam transformado os negros em tema de estudo, como se eles fossem em si mesmos um problema social".
} 
Autoras e autores referenciais no campo da pesquisa sobre Educação e Relações Raciais defendem que a população de origem africana, relegada à exclusão ou semi-incluída no sistema público educacional, criou suas próprias formas e espaços de educação e escolarização, ao mesmo tempo em que protagonizou e continua a ser protagonista das lutas travadas na construção de políticas educacionais que garantam a inserção qualificada dessa população nos sistemas públicos de ensino. Diante dessa realidade, indagamos se é possível reconhecer nas experiências educacionais negras elementos constitutivos de uma pedagogia decolonial. E, ainda, se práticas educativas vivenciadas por esses movimentos podem ser consideradas na gênese da luta por uma educação intercultural no Brasil.

Para avançar com essas questões, utilizamo-nos de um estudo bibliográfico por meio do qual buscamos construir um mapa de leitura das trajetórias históricas e experiências educativas vivenciadas pela população negra no Brasil, a partir das quais compreendemos que se instituiu e consolidou o que chamamos de um pensamento negro em educação, evidenciando aspectos teóricos que se aproximam das bases conceituais dos estudos póscoloniais latino-americanos.

O estudo centrou-se em duas fontes: textos referenciais escritos ou organizados por pesquisadoras e pesquisadores reconhecidos no âmbito da pesquisa sobre Educação e Relações Raciais no Brasil, tais como Petronilha Gonçalves e Silva, Luiz Alberto Gonçalves, Nilma Gomes, Cunha Júnior e Jeruse Romão, entre outros; e o relatório do VIII Encontro de Negros do Norte e Nordeste do Brasil, que ocorreu no Recife no ano de 1988.

As leituras sobre os estudos pós-coloniais latino-americanos foram aprofundadas a partir de textos de pesquisadores/as que compõem e rede modernidade/colonialidade, Anibal Quijano, Walter Mignolo, Maldonato-Torres e Catarine Walsh, entre outros/as.

Organizamos o texto em três partes: inicialmente, discutimos aspectos conceituais sobre a interculturalidade no pensamento decolonial; em seguida, abordamos a trajetória histórica de constituição do pensamento negro em educação; e, por fim, tentamos identificar aproximações e distanciamentos entre 
as experiências educativas dos movimentos negros no Brasil e as proposições conceituais do pensamento decolonial.

\section{A Interculturalidade no Pensamento Decolonial}

O pensamento decolonial da vertente latino-americana é marcadamente fundamentado nas ideias desenvolvidas por intelectuais integrantes do Movimento da Negritude ${ }^{4}$ como Aimé Césaire, Amílcar Cabral e Frantz Fanon, entre outros, apresentadas em trabalhos que datam da segunda metade do século $\mathrm{XX}$, tais como: a raça como elemento estrutural na hierarquização dos povos; a desumanização dos colonizados, que são transformados em "coisa"; a relevância da descolonização das mentes no processo de descolonização territorial; a necessidade de o colonizado desaprender para reaprender a sua própria humanidade. Algumas dessas ideias também estão presentes no pensamento do educador brasileiro Paulo Freire, que tem contribuído de forma significativa para a construção de uma educação humanizadora cuja produção tem referenciado nossos estudos.

No início do século XXI, tais ideias foram minuciosamente sistematizadas, aprofundadas e enriquecidas por intelectuais latino-americanos como Anibal Quijano, Walter Mignolo, Maldonato-Torres, Ramón Grosfoguel e Enrique Durcel, entre outros, e pela norte-americana Catarine Walsh, para constituir a teoria dos estudos pós-coloniais latino-americanos. Esses e outros intelectuais constituem o Grupo de Pesquisa Modernidade/Colonialidade que se reuniu pela primeira vez no início dos anos 2000, passando a atuar como uma rede de investigação e difusão de seus enfoques sobre as heranças coloniais na América Latina, considerando como eixo articulador o binômio modernidade/colonialidade (CASTRO-GOMES \& GROSFOGUEL, 2007).

A abordagem teórica, profundamente enraizada na dimensão do locus de enunciação - "o lugar geopolítico e corpo-político do sujeito que fala"

\footnotetext{
${ }^{4}$ Reação à branquitude reinante da cultura ocidental, sistematizada na França, na década de 1930, por um grupo de estudantes oriundos de países colonizados das Antilhas e da África. Surge inicialmente como movimento literário e posteriormente assume caráter político, ideológico e cultural. Na década de 1960, internacionalizou-se como um movimento de resgate da humanidade do negro, o qual se insurgiu contra o racismo imposto pelo branco no contexto da opressão colonial (Domingues, 2005).
} 
(GROSFOGUEL, 2010 p. 459) -, possui como questão central o desvelamento da articulação entre modernidade/colonialidade e suas implicações na organização da dominação eurocentrada.

O Pensamento Decolonial - como eixo de luta e ferramenta de análise aponta e quer transformar a matriz colonial presente em todos os países da América do Sul, que estruturou e mantém as relações de poder no Estado-Nação por meio do binômio colonialismo/colonialidade. Afirma Maldonato-Torre (2007 p. 131) que, "embora o colonialismo preceda a colonialidade, a colonialidade sobrevive ao colonialismo".

Conforme aponta Anibal Quijano (2007, p. 93), "a colonialidade é um dos elementos constitutivos do padrão mundial do poder capitalista". Diz respeito à distribuição do controle do poder mundial, que segundo o autor obedeceu a uma lógica de classificação e hierarquização baseada no eurocentrismo, que associou raça e divisão do trabalho para configurar um novo padrão mundial de controle do trabalho e, portanto, um novo padrão de poder que tomou a categoria raça como seu eixo articulador, revelando uma divisão racista do trabalho.

A colonialidade refere-se, portanto, à forma como o trabalho, o conhecimento, a autoridade e as relações intersubjetivas se articulam entre si por meio do mercado capitalista mundial e da ideia de raça (MALDONATOTORRE, 2007), expressando-se mediante quatro dimensões: a colonialidade do poder, a colonialidade do saber, a colonialidade do ser e a colonialidade da mãe natureza. Para Oliveira (2011), o conceito de colonialidade do ser abarca e explicita todos os outros. Refere-se à invenção e inculcação da não-existência dos povos subalternizados, configurando uma dominação psíquica, nos termos de Fanon (2005, p. 61), "um combate de retaguarda no terreno da cultura, dos valores, das técnicas, etc.". Por isso, acredita o autor, "a descolonização é verdadeiramente a criação de homens novos. Mas essa criação não recebe a sua legitimidade de nenhuma potência sobrenatural: a "coisa" colonizada se torna homem no processo mesmo pelo qual ela se liberta" (idem p. 53).

Para os pós-colonialistas latino-americanos, essa lógica de hierarquização e racialização eurocêntrica materializada na constituição dos Estados-Nação, transformou uma experiência local em padrão universal, negando e 
invisibilizando todas as outras culturas e formas de existência. Entretanto, por mais que sejam negadas e invisibilizadas as experiências não- ocidentais não deixaram de existir em função da universalização da experiência europeia.

$\mathrm{Na}$ realidade contemporânea, os modos de vida e de existência nãoeuropeus passam a ganhar relevância no processo de desconstrução de uma história única. De modo que o diálogo e as relações entre as culturas alcançam um lugar de destaque nesse processo. Como afirma Boaventura de Souza Santos (2011 p. 1), "o mundo diversificou-se, e a diversidade instalou-se no interior de cada país. A compreensão do mundo é muito mais ampla que a compreensão ocidental do mundo; não há internacionalismo sem interculturalismo".

Visibilizando os limites das perspectivas teóricas eurocêntricas, os estudos pós-colonialistas latino-americanos apontam para a necessidade de partirmos das experiências dos povos ancestrais para fundarmos um pensamento "outro"5 e construirmos um mundo "outro", nos quais exista a possibilidade de diálogo entre culturas.

De acordo com Vera Candau e Kelly Russo (2010), o termo interculturalidade surge na América Latina, no contexto educacional, e precisamente, com referência à educação escolar indígena, embora outros grupos tenham participado do processo de ampliação do debate sobre interculturalismo e educação. Segundo as autoras, a despeito de os grupos dos movimentos negros no continente se caracterizarem pela resistência e por suas lutas contra o racismo, portanto pelo reconhecimento de suas identidades culturais, "foi difícil encontrar na produção bibliográfica latino-americana sobre a educação intercultural referências às contribuições dos grupos e movimentos negros". (CANDAU e RUSSO, 2010 p. 158).

Contudo, no contexto brasileiro, Luiz Alberto Gonçalves e Petronilha Beatriz Gonçalves e Silva (2004) discutem as experiências da educação indígena e as experiências da educação de jovens e crianças negras, como movimentos por uma educação multiculturalista. E embora guardem profundas diferenças entre

5 Um pensamento construído por outras lógicas que não a racialização e racionalização eurocentrada. 
si, os termos interculturalidade e multiculturalidade têm sido utilizados, em alguns contextos, como sinônimos para fazer referência à existência de múltiplas culturas em um determinado lugar, defendendo seu reconhecimento, convivência e respeito. Afirmam esses autores que as primeiras iniciativas dos negros brasileiros para discutir questões referentes à pluralidade étnica, do país, data do final dos anos 40 do século XX.

Considerando a trajetória de surgimento das escolas bilíngues para a população indígena (a partir das primeiras décadas do referido século), Candau e Russo (2010) afirmam que "diferentes línguas foram o passo inicial para a proposição de um diálogo entre diferentes culturas" (p. 158). Entretanto, ao analisarmos as proposições de autores afiliados aos estudos pós-coloniais latino-americanos é possível afirmar que, para o Pensamento Decolonial, o diálogo entre culturas, a interculturalidade, não diz respeito apenas ao convívio ou à comunicação entre diferentes grupos. É algo mais complexo, mais profundo e mais transformador, porque está para além do respeito, da tolerância e do reconhecimento da diversidade, como veremos na continuação do texto.

Catherine Walsh (2010), considerou a variedade de contextos e interesses, nos quais se tem usado o termo interculturalidade para afirmar que podemos explicar esse termo a partir de três perspectivas. A autora chama de interculturalidade relacional "o contato e intercâmbio entre culturas, quer dizer, entre pessoas, práticas, saberes, valores e tradições culturais distintas, que podem se dar em condições de igualdade ou desigualdade" (WALSH, 2010 p. 77); considera a proposição do filósofo peruano Fidel Tubino para denominar como interculturalidade funcional "o reconhecimento das diversidades e das diferenças culturais, com o objetivo da inclusão destas no interior das estruturas sociais já estabelecidas7" (idem). Para a autora, essa perspectiva é funcional à lógica do modelo neoliberal existente, porque busca promover o diálogo, a convivência e a tolerância, mas não questiona as causas das desigualdades sociais e culturais, não modifica as estruturas de poder. Por isso, vários autores

\footnotetext{
${ }^{6}$ Tradução nossa.

7 Tradução nossa.
} 
têm se referido a essa perspectiva como "a nova lógica multicultural do capitalismo global".

Por fim, Walsh define e assume a interculturalidade crítica como sendo "o reconhecimento de que a diferença se constrói dentro de uma estrutura e matriz colonial de poder racializado e hierarquizado, com os brancos e "branqueados" em cima e os povos indígenas e afrodescendentes nos degraus inferiores" (WALSH, 2010 p. 78). Afirma a autora que a interculturalidade crítica ainda não existe, é algo por construir. É compreendida como estratégia, ação e processo permanentes de relação e negociação entre, em condições de respeito, legitimidade, simetria, equidade e igualdade. É assumida como um projeto político, social, ético e epistêmico, que afirma a necessidade de mudar não só as relações, mas também as estruturas, condições e dispositivos de poder que mantém a desigualdade, inferiorização, racialização e descriminalização, inclusive no âmbito educacional.

Walsh (2009) explica ainda que o conceito de interculturalidade está intimamente ligado ao conceito de plurinacionalidade. Baseando-se na noção de ambiguidade fundacional, a autora nos leva a compreender que todos os Estados-Nação da América do Sul foram fundados como Estados que possuem caráter uninacional e natureza monocultural (negando e invisibilizando outros povos e culturas, enquanto afirmavam o ideário europeu/ocidental), embora concretamente sejam constituídos por povos e culturas distintas. O discurso da mestiçagem (utilizado de múltiplas formas nos diversos países da América Latina) gerou uma noção abstrata de inclusão, mas uma prática concreta de exclusão. E a lógica multicultural atua hoje no sentido de reconhecer e incluir a diversidade cultural, porém mantendo a estrutura do Estado-Nação.

Para Walsh, é por isso que em muitos momentos se utilizam os termos multiculturalidade, pluriculturalidade e interculturalidade (inclusive de forma oficial) como se eles fossem sinônimos. A autora refere-se a esse processo como uma recolonialidade: "No capitalismo global da atualidade, opera uma lógica multicultural que incorpora a diferença, na medida em que a neutraliza e

8 Tradução nossa. 
a esvazia de seu significado efetivo" (WALSH, 2009 p.132). Assim, a plurinacionalidade seria o eixo do projeto intercultural que trata da transformação da matriz colonial a partir da transformação do Estado-Nação (uninacional, colonial e excludente) para um Estado Plurinacional construído a partir das diferenças ancestrais.

A plurinacionalidade e a interculturalidade são projetos decoloniais que se propõem, portanto, a fundar um pensamento "outro", ao reconceituar e refundar estruturas sociais, epistêmicas e de existências que põem em cena e em relação equitativa lógicas, práticas e modos culturais diversos de pensar, atuar e viver. Nas palavras de Walter Mignolo (2008), a opção decolonial é imaginar um mundo no qual muitos mundos podem existir em conjunto. Assim, a opção decolonial significa entre, outras coisas, aprender a desaprender para poder aprender novamente de outra forma.

Segundo Walsh (2009, p. 140),

Como projeto político, social, epistêmico e ético, a interculturalidade crítica expressa e exige uma pedagogia e uma aposta e prática pedagógicas que retomam a diferença em termos relacionais, com seu vínculo histórico-político-social e de poder, para construir e afirmar processos, práticas e condições distintas. Dessa maneira, a pedagogia é entendida além do sistema educativo, do ensino e transmissão do saber. É também processo e prática sociopolíticos produtivos e transformadores, assentados nas realidades, subjetividades, histórias e lutas das pessoas que vivem num mundo regido pela estrutura colonial (tradução nossa).

A essa pedagogia solicitada pela interculturalidade crítica a autora chamou pedagogia decolonial. Para ela, embora a pedagogia decolonial possua elementos comuns à pedagogia crítica anunciada por Paulo Freire a partir dos anos 1960, as pedagogias decoloniais incorporam a categoria raça como eixo articulador, como proposto por Frantz Fanon. E, dessa forma, sugere a autora que as pedagogias decoloniais são aquelas capazes de, cruzando essas duas vertentes contextuais do "pensar a partir da" condição ontológico-existencial-

9 Tradução nossa. 
racializada dos colonizados e do "pensar com" outros setores populares, fazer insurgir, reviver e reexistir.

Dessa forma, a genealogia da pedagogia decolonial está nas lutas e práticas próprias dos povos ancestrais africanos e indígenas, que foram subalternizados na relação colonialismo/colonialidade e que, portanto, tiveram essas suas práticas, conhecimentos e formas de organização invisibilizadas. Isso não significa que elas não existissem, como é possível perceber no caso dos movimentos sociais negros brasileiros, foco deste trabalho.

\subsection{Pensamento Negro em Educação no Brasil: acesso, presença e pertença da população negra à educação escolarizada}

A população de origem africana no Brasil desde sempre expressou suas concepções e orientações, conforme apontam Petronilha Gonçalves e Silva e Lúcia Barbosa (1997), tendo em vista a educação de suas crianças e adolescentes dentro e fora dos processos formais de escolarização.

Mariléia Cruz (2005, p. 21) afirma que o fato dos negros darem corpo a intervenções sociais no campo intelectual nos primeiros anos da Republica, por meio das organizações negras, da criação de escolas e da imprensa negra, sinaliza para a existência de processos de escolarização vivenciados pelos negros desde o período da escravidão. "A necessidade de ser liberto ou de usufruir a cidadania quando livre, tanto durante os períodos do Império quanto nos primeiros anos da República, aproximou as camadas negras da apropriação do saber escolar, nos moldes das exigências oficiais" (CRUZ, 2005, p. 27). A escolarização dessa população caracteriza-se, portanto, nesse primeiro momento, como luta por reconhecimento e inclusão social.

A escola, como instituição moderna criada como espaço de disseminação do conhecimento, foi considerada um instrumento capaz de fazer ascender socialmente. Para a população negra, desprovida de bens materiais, esse espaço apresentou-se quase como a única oportunidade de conquistar algum prestígio social (SILVA, 2013).

Ao olharmos para a trajetória de luta dos movimentos negros brasileiros pela educação escolarizada, é possível identificarmos três diferentes 
movimentos de aproximação e vivência da escolarização: a) escolarização como portal, b) escolarização como espelho e c) escolarização como enraizamento.

No primeiro momento, a escolarização foi vista como um portal poderoso para a inclusão social e para o reconhecimento da população negra na sociedade brasileira. Embora encontrem-se evidências do acesso da população negra a escolas e outras instituições de instrução públicas já a partir da segunda metade do século XIX (CRUZ, 2005; ARANTES, 2005), esse segmento criou suas próprias escolas e empreendeu esforços diversos, desde o período do Império, que Ihes garantiram a apropriação dos saberes formais exigidos socialmente. Mariléia Cruz apresenta alguns exemplos (2005, p. 28): o Colégio Perseverança ou Cesarino, fundado em Campinas (SP), em 1860; o Colégio São Benedito, também em Campinas (SP), em 1902; as aulas públicas oferecidas pela Irmandade de São Benedito, em São Luiz do Maranhão; a escola de Ferroviários de Santa Maria, no Rio Grande do Sul; e os cursos de alfabetização, primário e preparatório para o ginásio oferecidos pela Frente Negra Brasileira.

Os estudos de Luz (2008) sobre a Sociedade dos Artistas, Mecânicos e Liberais de Pernambuco revelam que essa Associação promoveu um trabalho de profissionalização e instrução para operários jovens e adultos no Recife, na primeira metade do século XIX. Segundo o autor, o trabalho da associação "culminou na instalação do Liceu de Artes e Ofícios de Pernambuco, no final do mesmo século" (LUZ, 2008, p. 17). Essas iniciativas são indícios de que o movimento negro brasileiro sempre considerou a educação escolar como um portal poderoso para ascensão social de seu povo. Além de promover os seus próprios processos de escolarização, reivindicou e continua a reivindicar a inclusão da população negra na escola pública em todos os níveis de ensino. Entretanto, o acesso de camadas da população negra à escola, por meio da política de universalização do ensino, não resolveu o problema das desigualdades étnico-raciais na educação.

Conforme chama a atenção Henriques (2001), a discrepância na escolaridade entre brancos e negros é em média de 2,3 anos de estudos. Essa desigualdade tem se mostrado intergeracional, pois é praticamente a mesma para um jovem hoje como foi para seus pais e avós. Do ponto de vista qualitativo, 
Paixão (2003) elenca alguns vetores de produção das desigualdades étnicoraciais no sistema de ensino brasileiro: a discriminação no espaço escolar, a imagem e a representação da população negra nos parâmetros curriculares e no material didático escolar e paraescolar e a importância da família na reprodução intergeracional das condições de vida e na confirmação ou superação das situações problemáticas vivenciadas no espaço escolar.

No segundo movimento, a escolarização pode ser entendida como um espelho no qual a população negra se olha, mas não se vê, não se encontra nas imagens refletidas. Caracteriza-se como um momento de questionamento da negação e da invisibilidade da população negra no espaço escolar, seja nos conteúdos disciplinares, no material didático, nos murais das instituições escolares. A população negra passa a reivindicar a sua existência física e a exigir a sua presença no espaço escolar. Esse período é fortemente marcado pela denúncia da escola como espaço de produção e reprodução de práticas racistas e discriminatórias.

O VIII Encontro de Negros do Norte e Nordeste realizado no Recife, em julho de $1988^{10}$, teve como preocupação central "questionar a negação da importância do negro na formação social brasileira, através dos meios oficiais de educação do país" ${ }^{11}$. As proposições construídas apontam para a necessidade de introduzir o estudo da História da África nos currículos escolares; discutir o papel da professora e do professor na descolonização do ensino e considerar a aprendizagem pela prática cultural como elementos importantes para o sucesso do processo de ensino/aprendizagem da população negra.

Os blocos afros, em Salvador (BA), a partir dos anos de 1980, o Centro Maria da Conceição (1982) e o Grupo Cultural Daruê Malungo (1990), no Recife (PE), são exemplos de experiências educativas iniciadas nas décadas de 1980 e 1990, que se estruturam tomando a aprendizagem pela prática cultural como elemento fundante do processo de ensino e de aprendizagem. Embora

\footnotetext{
10 O encontro, já referido na introdução desse trabalho, teve como tema "O Negro e a Educação" e é uma ação que acontece nesse movimento de questionamento da negação e da invisibilidade da população negra no espaço escolar.

${ }^{11}$ Dados disponíveis. In: NEGRO E EDUCAÇÃO. Relatório do VIII Encontro dos Negros do Norte e Nordeste do Brasil. Recife: Movimento Negro Unificado, 1988.
} 
objetivassem possibilitar o sucesso na educação escolar de crianças e jovens negros conforme o modelo oficial (ocidental/eurocêntrico), tais práticas são fundamentadas nas lutas, nas experiências e nos conhecimentos próprios dos povos de origem africana no Brasil, o que as aproxima daquilo que Walsh (2009) define como uma pedagogia decolonial. A aprendizagem pela prática cultural faz referência a uma educação que é assentada na cultura afro-brasileira e africana e toma como princípios orientadores a ancestralidade, a identidade e a resistência dos africanos e seus descendentes.

Finalmente, o terceiro movimento é aquele que estamos buscando vivenciar na contemporaneidade. A escolarização como forma de enraizamento. É um momento revelador da heterogeneidade da escola e da necessidade de reconhecimento e acolhimento dessa heterogeneidade como elemento fundamental para o sucesso do processo de ensino-aprendizagem. Trata-se de um período de busca e apropriação das histórias e das subjetividades negadas, mas que não deixaram de existir. Momento no qual a centralidade da cultura ganha contornos nos processos educativos. A figura a seguir sintetiza as características dos três movimentos referidos:

\section{Figura 01 - Movimentos de aproximação e vivência da população negra com a escolarização}

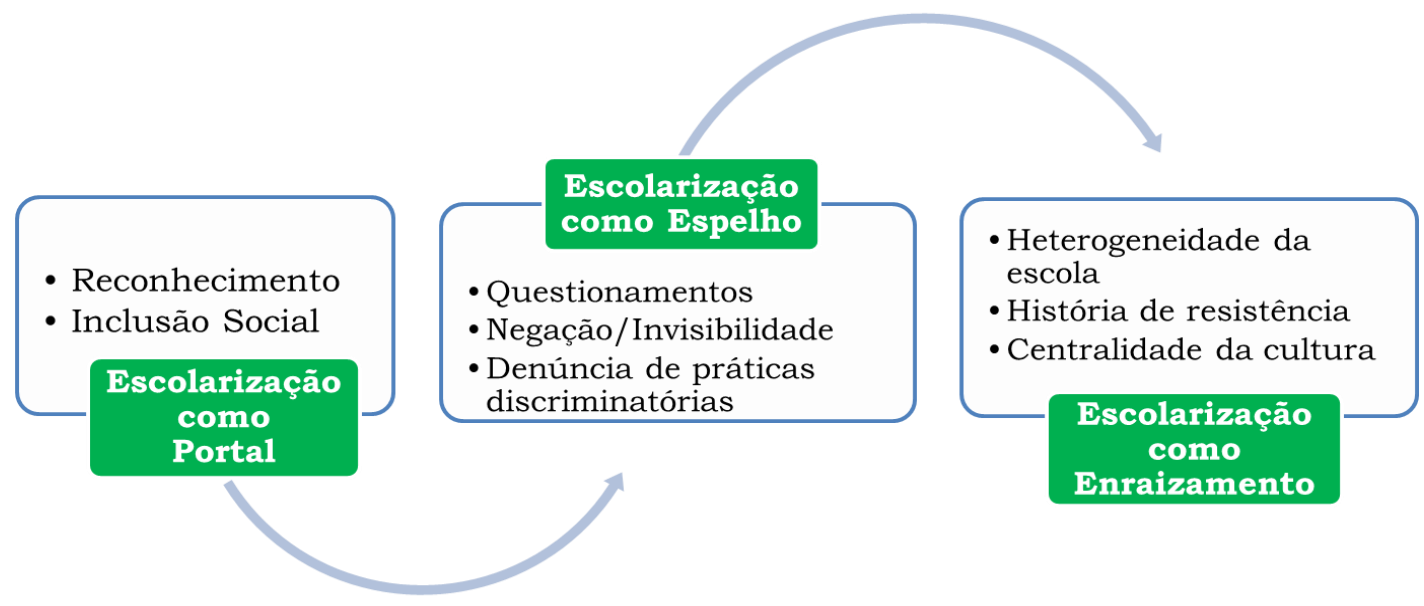

Fonte: elaboração própria.

Na condição de movimentos de aproximação e vivência, vale destacar que não se trata de momentos lineares ou superados. Nas diversas realidades 
brasileiras, esses movimentos se entrecruzam, se distanciam e, em alguns contextos, coexistem simultaneamente.

Gomes (1997), ao discutir a contribuição dos negros para o pensamento educacional brasileiro, conclui que o olhar do movimento negro para a educação trouxe, para além das reivindicações, problematizações teóricas e ênfases específicas que dão materialidade a um pensar sobre a educação, construído a partir do ponto de vista do povo negro. A autora sistematiza essa contribuição em 05 aspectos: 1) a denúncia de que a escola reproduz e repete o racismo presente na sociedade; 2) a ênfase na história de luta e resistência do povo negro; 3) a afirmação da existência de uma produção cultural realizada pelos negros, com uma história ancestral que nos remete à nossa origem africana; 4) a consideração de que existem diferentes identidades no espaço escolar; e 5) a denúncia de que a estrutura excludente da escola precisa ser reconstruída para garantir o acesso à educação, a permanência e o êxito dos alunos de diferentes pertencimentos étnico-raciais e níveis socioeconômicos.

A partir das reivindicações de acesso da população negra à instituição escolar e da inclusão da história e cultura afro-brasileira nos currículos escolares, os movimentos negros brasileiros problematizaram a existência de valores e práticas discriminatórias na escola, principalmente quando essa instituição nega a existência da diferença em seus domínios. Revelou a heterogeneidade da escola e enfatizou a história de luta e resistência da população negra (uma vez que a escola apenas oferecia a história de sua escravidão) e a centralidade da cultura nos processos educacionais do povo negro. Configurou dessa forma um pensamento sobre a educação constituído a partir de suas práticas e vivências educacionais construídas, na maioria das vezes, alternativamente aos processos de educação formal (SILVA, 2013).

O pensamento negro em educação no Brasil trata-se, portanto, de um conjunto de ideias e práticas educativas que foram sendo construídas a partir das experiências vivenciadas por ativistas e/ou organizações do movimento negro brasileiro, com a intenção de prover uma educação de efetiva qualidade para a população negra. 
Ao examinarmos os anos de luta por uma educação antirracista e uma aprendizagem significativa para a população negra, encontramos iniciativas educativas diversas, e em diferentes regiões do país, destinadas a diferentes níveis e modalidades de ensino: são intervenções pedagógicas, práticas de ensino-aprendizagem, projetos político-pedagógicos e propostas educacionais, que em dados momentos são denominadas pedagogias. Dentre estas, destacamos: a Pedagogia Interétnica de Salvador, proveniente do Núcleo Cultural Afro-Brasileiro, que data de 1978; a Pedagogia Multirracial, formulada por Maria José Lopes da Silva, no Rio de Janeiro, em 1986; a Pedagogia Multirracial e Popular proposta pelo Núcleo de Estudos Negros, em Santa Catarina, em 2001 (LIMA, 2004, 2011). Em Salvador, ainda é possível apontar a Pedagogia Nagô, também referida como Mito-Pedagogia (a partir de 1999), vivenciada na escola do terreiro llê Axé Opô Afonjá (MOLINA, 2011).

Essas e outras iniciativas educativas tomam a história e cultura afrobrasileira como bases de sua ação pedagógica e possuem como fundamento o combate permanente ao racismo, a afirmação da identidade da população negra e a superação das desigualdades étnico-raciais. Em sintonia com as circunstâncias, possibilidades, contextos e momento histórico em que cada uma delas foi elaborada, orientam-se por diversas teorias, sempre em complementariedade, tais como: o Multiculturalismo Crítico e a Afrocentricidade, ambas desenvolvidas nos Estados Unidos; a Educação Popular vivenciada no Brasil e na América Latina; a Tradição Oral dos povos ancestrais; e o Pensamento do educador brasileiro Paulo Freire, que é evidenciado em todas as iniciativas educativas que foram citadas.

\subsection{Algumas Considerações: encontrando convergências e aproximando caminhos}

A trajetória da luta dos movimentos negros brasileiros por educação nos revela a existência e vivência de situações que se aproximam do que o militante afro-equatoriano Ruan García tem se referido como o conhecimento casa adentro. Segundo Walsh (2007), Garcia utiliza essa expressão para designar os processos internos das organizações e comunidades para construir e fortalecer 
um pensamento e um conhecimento próprios. Para o afro-equatoriano, sem conhecimentos próprios não podemos construir a interculturalidade.

Se não temos conhecimento casa adentro, não podemos dialogar com outros conhecimentos casa a fora. Alguns autores/as afro-brasileiros, como Célia Azevedo, têm se referido a esses mesmos processos com os termos "da porteira pra dentro" e " da porteira pra fora”. Conforme Molina (2013), termos cunhados por Mãe Senhora (terceira lalorixá ${ }^{12}$ do terreiro Ilê Axé Opô Afonjá, localizado em Salvador na Bahia) para sinalizar as esferas de saber e de poder que os membros da sua comunidade precisavam aprender a frequentar: o diploma e o orgulho do pertencimento étnico-racial.

Mãe Senhora seguia os passos de Mãe Aninha (lalorixá fundadora do terreiro llê Axé Opô Afonjá), que nos anos 1970 acolheu a primeira experiência escolar num terreiro de Candomblé que se propunha, com uma pedagogia a partir de dramatizações de contos afro-brasileiros, escolarizar as crianças por meio da conexão com suas origens africanas ${ }^{13}$. Mãe Aninha se tornou símbolo da luta da comunidade negra brasileira por uma educação antirracista, pois a ela é atribuída a celebre frase: "Quero ver as crianças de hoje, no futuro, de anel no dedo e aos pés de Xangô”.

Percebemos, assim, que embora o movimento de aproximação da população negra brasileira da educação escolarizada visasse à sua inclusão e ao reconhecimento na sociedade, tendo se dado "nos moldes da educação oficial" (CRUZ, 2005), portanto eurocentrada, não se pode negar a existência de tentativas de construir ações a partir dos conhecimentos próprios, que podem ser entendidas como práticas de enfrentamento e desconstrução do eurocentrismo.

Petronilha Gonçalves e Silva e Lúcia Barbosa (1997) afirmam que as ações educativas deliberadamente concebidas e vivenciadas pelos movimentos negros brasileiros buscam as primeiras referências nas civilizações africanas anteriores

\footnotetext{
12 lalorixá é uma sacerdotisa, uma liderança religiosa do Candomblé, uma zeladora de orixás (as divindades iorubanas trazidas para o Brasil na diáspora negra).

${ }^{13}$ Trata-se da Mini Comunidade Obá Biyi, um projeto piloto envolvendo educação escolar na comunidade do terreiro llê Axé Opô Afonjá, fundado em 1978 com o intuito de complementar o ensino da escola oficial de primeiro grau ou iniciar o processo de escolarização através da creche e da pré-escola (MOLINA, 2013).
} 
à colonização europeia, e a elas seguem-se novas referências criadas nas diferentes circunstâncias históricas. Ou seja, existe uma constante tensão entre a manutenção da lógica eurocêntrica (a colonialidade do saber, a geopolítica do conhecimento) e a proposição epistêmica dos descendentes de africanos no Brasil. Existe um pensamento negro construído a partir das experiências dessa população que foi negado e invisibilizado ao longo da história do Brasil.

Essas ações são pensadas e executadas em paralelo com a busca de reconhecimento e inclusão da população negra nos sistemas de ensino oficiais, mas com o mesmo ponto de referência: combater o racismo e as desigualdades raciais, visibilizar a diferença colonial na perspectiva da população negra e construir possibilidades de convivência, equitativa e respeitosa, entre todos os habitantes do território do Brasil. Ou seja, o que se pretende com o reconhecimento da população negra não é apenas a inclusão dessa população na sociedade brasileira, mas também a inclusão de suas formas de pensar, de se organizar e de existir.

Gomes (2010, p. 493) afirma que:
A inserção de negros e negras no campo da pesquisa científica e da produção do conhecimento, não mais como objetos de estudo, mas como sujeitos que possuem e produzem conhecimento, faz parte da história de lutas sociais em prol do direito à educação e ao conhecimento, assim como da luta pela superação do racismo.

Segundo a autora, esses e outros pesquisadores oriundos de diferentes grupos sociais e étnicos, ao se inserirem nas universidades, desencadeiam um outro tipo de produção do conhecimento, um conhecimento realizado 'por' esses sujeitos, que privilegia a parceria 'com' os movimentos sociais ao invés de produzir conhecimento 'sobre' esses movimentos e seus sujeitos. Um conhecimento que se constrói, portanto, a partir da diferença colonial e busca evidenciar um "pensamento outro", um dos conceitos fundantes do pensamento decolonial.

É trilhando esse caminho que os movimentos negros do Brasil chegam à proposição da Lei no 10.639/03, a alteração da LDB no 9394/96, e com ela a proposição de modificações na estrutura da sociedade brasileira. 
A alteração da LDB 9394/96 pela Lei no 10.639/03 propõe transformar a inclusão da educação das relações étnico-raciais e da História e Cultura AfroBrasileira nos currículos escolares em política pública de educação (BRASIL, 2004). Para Nilma Gomes (2009), a alteração vincula-se à garantia do direito à educação e requalifica esse direito ao acrescer-lhe o direito à diferença. A lei exige que se repensem as bases das relações étnico-raciais, sociais e pedagógicas sobre as quais se assenta a política educacional brasileira. Ela propõe-se a modificar a escola, mexendo com a estrutura da instituição, uma vez que exige a mudança de atitude dos atores da comunidade escolar em seus mais diversos níveis de atuação.

Ainda segundo Nilma Gomes:

Com avanços e limites, a Lei $10.639 / 03$ e suas diretrizes curriculares possibilitaram uma inflexão na educação brasileira. Elas fazem parte de uma modalidade de política até então pouco adotada pelo Estado brasileiro e pelo próprio MEC. São políticas de ação afirmativa voltadas para a valorização da identidade, da memória e da cultura negras. (2009, p. 40).

Ao considerarmos que o racismo antinegro constitui elemento estruturador das relações sociais e institucionais estabelecidas no Brasil, podemos concluir que, por consequência, a Lei no 10.639/03 propõe modificações para a estrutura da própria sociedade brasileira. Partindo desse princípio, não será difícil compreender o nascedouro das dificuldades vivenciadas e enfrentadas no exercício de sua implementação. Tais dificuldades são reflexos da ideia enraizada de inferioridade do negro e superioridade do branco, fundada na colonialidade do ser, que justifica o racismo e as desigualdades étnico-raciais no país.

Entretanto, como sugere Oliveira (2011), como possibilidade, ela é um instrumento que pode criar as condições para a transformação das relações de subalternidade na educação brasileira, pois se propõe a ampliar o foco dos currículos, assumindo novas abordagens interpretativas sobre a identidade nacional, com alguns pressupostos não-eurocêntricos. Nesse processo, a formação dos professores/as ganha papel relevante, uma vez que "o desafio de contar e aprender uma história outra e fazer dela um elemento de novas 
perspectivas políticas, epistemológicas e indenitárias nos processos educacionais" (OLIVEIRA, 2011, p. 11) não está mais apenas a cargo dos movimentos negros, mas de todos os profissionais da educação. Todavia, concordamos com o autor que esse continua sendo um campo de disputas, conflitos e negociações. E, portanto, "a produção de novas enunciações e espaços de enunciações" dependerá, durante muito tempo ainda, da capacidade de luta e organização coletiva da população negra brasileira para dar materialidade à intencionalidade da lei e suas diretrizes.

Diante das reflexões apresentadas, consideramos que o pensamento negro em educação, em diálogo com o pensamento de Paulo Freire, aponta elementos que podem configurar uma pedagogia decolonial da população negra no Brasil. Uma pedagogia que se concretiza por meio um pensar e agir pedagógico de permanente combate ao racismo. Que se organiza por meio da interdisciplinaridade e aposta em processos geradores de autoestima e orgulho do pertencimento étnico-racial; nela a intervenção pedagógica é uma vivência e por isso possibilita uma aprendizagem significativa; a problematização do conhecimento é contextualizada pela contação de histórias como princípio organizador do trabalho pedagógico (mitos, literatura afro-brasileira, lendas etc.). E os conhecimentos disciplinares caminham lado a lado com os valores, normas e atitudes que são relevantes para a comunidade negra, uma vez que seus princípios orientadores são a ancestralidade, a identidade e a resistência dos africanos e seus descendentes.

Trata-se de uma pedagogia que se coloca a serviço da eliminação das desigualdades raciais, sociais e educativas, se propondo a enfrentar "o mito racista que inaugura a modernidade [...] e o monólogo da razão modernoocidental" (BATISTA, 2009, apud WALSH, 2009). Assim, compõe o conjunto das pedagogias que se esforçam, como define Walsh (2009, p. 141), por "transgredir, deslocar e incidir na negação ontológica, epistêmica e cosmogônico-espiritual", caracterizando-se como uma das pedagogias que integram o questionamento e a análise crítica, a ação social transformadora, embora ainda tenha muito a caminhar em busca de também incidir na insurgência e intervenção nos campos do poder, saber, ser e na vida, no sentido de implodir a matriz colonial. 
Conta-se que:

antes de deixar o porto do Ouidah, na atual República do Benin, os africanos escravizados eram levados à árvore do esquecimento - plantada pelo rei Agadja em 1727. Depois de nove voltas dadas pelos homens - as mulheres davam sete acreditava-se que origens, identidade cultural, lembranças de suas moradas e de suas localizações geográficas perdiam-se no limbo. A memória era reconhecida pelos mercadores de escravos como uma poderosa arma de resistência. Ao que parece, eles estavam certos em relação à força da memória ${ }^{14}$.

Todavia, compartilhamos com os autores do texto citado anteriormente a ideia de que o poder da árvore pode ser questionado exatamente pelo fato da sobrevivência da raiz indenitária africana no Brasil e na diáspora negra.

Consideramos que as práticas educativas concebidas e executadas pelos movimentos negros no Brasil, assim como suas ações para incluir e disseminar os estudos sobre a história e cultura afro-brasileira e africana nos currículos escolares, são resultados dos esforços dessa população para dar a volta inversa na árvore do esquecimento e, dessa forma, reencontrar-se, refundar-se, reexistir.

\section{Referências}

ARANTES, Adlene Silva. O papel da Colônia Orfanológica Isabel na educação e na definição dos destinos de meninos negros, brancos e índios na Província de Pernambuco (1874-1889). 2005. Dissertação (Mestrado em Educação) - Centro de Educação, Universidade Federal de Pernambuco, Recife, 2005.

BRASIL. Diretrizes Curriculares Nacionais para a Educação das Relações ÉtnicoRaciais e para o Ensino de História e Cultura Afro-Brasileira e Africana. Brasília: MEC, 2004.

CANDAU, Vera Maria Ferrão; RUSSO, Kelly. Interculturalidade e Educação na América Latina: uma construção plural, original e complexa. Revista Diálogo Educacional, Curitiba, vol. 10, n. 29, pp. 151-169, janeiro-abril, 2010.

CASTRO-GOMES, Santiago; GROSFOGUEL, Ramón (Org.). El Giro Decolonial: reflexiones para una diversidad epistémica más allá del capitalismo global. Bogotá:

14 Disponível em http://diariodoandre.com/2010/8/12/volta-inversa-na-arvore-do-esquecimento/ Acesso em 21 de maio de 2012. 
Siglo del Hombre Editores; Universidad Central - Instituto de Estudios Sociales Contemporáneos y Pontificia Universidad Javeriana - Instituto Pensar, 2007.

CRUZ, Mariléia dos Santos. Uma Abordagem sobre a História da Educação dos Negros. In: ROMÃO, Jeruse. História da Educação do Negro e Outras Histórias. Brasília: Secretaria de Educação Continuada, Alfabetização e Diversidade /Ministério da Educação, 2005. (Coleção Educação para Todos).

CUNHA Jr., Henrique. Metodologia Afrodescendente de Pesquisa. Texto de Trabalho na disciplina de Educação Gênero e Etnia na perspectiva dos Afrodescendentes, 2006. Disponível em: http://afrobrasileira.multiply.com/journal/item/ 52?\&show_interstitial=1\&u=\%2Fjournal\%2Fitem. Acesso em 5 de abril de 2011.

DOMINGUES, Petrônio. Movimento da Negritude: uma breve reconstrução histórica. In: Mediações - Revista de Ciências Sociais, Londrina, v. 10, n.1, p. 25-40, jan.-jun. 2005.

FANON, Frantz. Os Condenados da Terra. Tradução: Elnice Albergaria Rocha; Lucy Magalhães. Juiz de Fora, MG: Ed. UFJF, 2005.

GOMES, Nilma Lino. A Contribuição dos Negros para o Pensamento Educacional Brasileiro. In: SILVA, Petronilha Beatriz Gonçalves; BARBOSA, Lúcia Maria de Assunção (Org.). O pensamento negro em educação no Brasil: expressões do movimento negro. São Carlos, SP: Ed. da UFSCar, 1997.

Limites e Possibilidades da Implementação da Lei 10.639/03 no Contexto das Políticas Públicas em Educação. In: PAULA, Marlene; HERINGER, Rosana (Orgs.). Caminhos Convergentes: Estado e Sociedade na superação das desigualdades raciais no Brasil. Rio de Janeiro: Fundação Heinrich Boll, ActionAid, 2009.

Intelectuais negros e produção do conhecimento: algumas reflexões sobre a realidade brasileira. In: SANTOS, Boaventura de Sousa; MENESES, Maria Paula (Orgs.). Epistemologias do Sul. São Paulo: Cortez, 2010.

GONÇALVES, Luiz Alberto Oliveira; GONÇALVES E SILVA, Petronilha Beatriz. 0 Jogo das Diferenças: o multiculturalismo e seus contextos. 3. ed. $2^{a}$ reimp. Belo Horizonte: Autentica, 2004.

GONÇALVES e SILVA, Petronilha Beatriz; BARBOSA, Lúcia Maria de Assunção (Orgs.). O Pensamento Negro em Educação no Brasil: expressões do movimento negro. São Carlos, SP: EdUFSCar, 1997.

GROSFOGUEL, Ramón. Para descolonizar os estudos de economia política e os estudos pós-coloniais: transmodernidade, pensamento de fronteira e colonialidade global estudos. In: SANTOS, Boaventura de Sousa; MENESES, Maria Paula (Orgs.). Epistemologias do Sul. São Paulo: Cortez, 2010.

HENRIQUES, Ricardo. Texto para Discussão no 807 - Desigualdade Racial no Brasil: evolução das condições de vida na década de 90 (2001). Disponível em http:// www.ipea.gov.br acesso em 5/4/2009. 
LIMA, Ivan Costa. Uma Proposta Pedagógica do Movimento Negro no Brasil: pedagogia interétnica de Salvador, uma ação de combate ao racismo. Dissertação (Mestrado em Educação) - Programa de Pós-Graduação em Educação, Universidade Federal de Santa Catarina, Florianópolis, 2004.

Nossas Persistências Históricas: caminhos das pedagogias do Movimento Negro no Brasil. In: Saeculum - Revista de História, João Pessoa - Paraíba, nº 25, p. $141-159$, jul./ dez. 2011.

LUZ, Itacir Marques. Compassos Letrados: profissionais negros entre instrução e ofício no Recife (1840 - 1860). 2008. Dissertação (Mestrado em Educação) Programa de Pós-Graduação em Educação, Universidade Federal da Paraíba, João Pessoa, 2008.

MALDONADO-TORRES, Nelson. Sobre la colonialidad del ser: contribuciones al desarrollo de un concepto. In: CASTRO-GÓMEZ, Santiago. e GROSFOGUEL, Ramón. (Orgs.). El giro decolonial. Reflexiones para una diversidad epistémica más allá del capitalismo global. Bogotá: Universidad Javeriana-Instituto Pensar/Universidad Central-IESCO/Siglo del Hombre Editores, 2007.

MIGNOLO, Walter D. Desobediência Epistêmica: a opção descolonial e o significado de identidade em política.Cadernos de Letras da UFF - Dossiê: Literatura, língua e identidade, no 34, p. 287-324, 2008.

MOLINA, Thiago dos Santos. A didática da dupla consciência e o ensino de história e cultura afro-brasileira e africana. Trabalho apresentado na 36 ${ }^{a}$ Reunião Nacional da ANPEd - GT 21 - Goiânia-GO, 2013.

A Didática da Dupla Consciência e o Ensino de História e Cultura AfroBrasileira e Africana. Trabalho apresentado na 36를 Reunião Nacional da ANPEd - GT 21, Goiânia-GO, 2011.

\section{NEGRO E EDUCAÇÃO. Relatório do VIII Encontro dos Negros do Norte e} Nordeste do Brasil. Recife: Movimento Negro Unificado, 1988.

OLIVEIRA, Luiz Fernandes. Histórias da África e dos Africanos na Escola: tensões políticas, epistemológicas e indenitárias na formação docente. Anais do XXVI Simpósio Nacional de História - ANPUH, p. 1-18, São Paulo, julho 2011.

QUIJANO, Aníbal. Colonialidad del poder y clasificación social. In: CASTRO-GÓMEZ, Santiago e GROSFOGUEL, Ramón. (Orgs.). El giro decolonial. Reflexiones para una diversidad epistémica más allá del capitalismo global. Bogotá: Universidad Javeriana-Instituto Pensar / Universidad Central-IESCO / Siglo del Hombre Editores, p. 93-126, 2007.

SANTOS, Boaventura de Sousa. Carta às Esquerdas (24/8/2011). Disponível em: http://www.cartamaior.com.br/templates/colunaMostrar.cfm?coluna id=5169 [acesso em 23 de setembro de 2012]. 
SILVA, Claudilene. Professoras Negras: identidades e práticas de enfrentamento do racismo no espaço escolar. Recife: Ed. Universitária da UFPE, 2013 (Coleção Etnicorracial).

WALSH, Catherine. Interculturalidad crítica y educación intercultural. In: VIAÑA, Jorge; TAPIA, Luis; WALSH, Catherine. Construyendo Interculturalidad Crítica. La Paz - Bolivia. Instituto Internacional de Integración del Convenio Andrés Bello. III CAB, 2010.

- Interculturalidad Crítica y Pedagogia De-Colonial: in-surgir, re-existir y re-vivir. Revista "Entre palabras", Fac. Humanidades y Ciencias de la Educación, No.3 No.4, UMSA, La Paz - Bolívia, p 129-156, 2009.

Interculturalidad, Plurinacionalidade y Decolonialidad: las insurgencias político-epistémicas de refundar el Estado. In: Revista Tabula Rasa, Bogotá Colombia, no 9, p. 131-152, julio-diciembre, 2008.

Interculturalidad, colonialidade y educación. Revista Educación y

Pedagogia, Medellín, Universidade de Antioquia, Facultad de Educación, vol. XIX, n. 48, p. 25 - 35, Mayo -Agosto, 2007. 